\title{
NOTAS LINGUISTICAS A DOCUMENTOS MEDIEVALES MURCIANOS (1243-1283)
}

Por

MARIA DEL PILAR DIEZ DE REVENGA 
En la realización del presente trabajo $\left(^{\circ}\right)$ nuestro interés se ha centrado en la situación sumamente problemática del estado de lengua existente en el Reino de Murcia en el período comprendido entre los años 1243 y 1283. La tan conocida y repetida afirmación del gran cronista catalán Ramón Muntaner: "Si que siats certs que tots aquells qui en la dita ciutat de Murcia (...) son vers catalans e parlen de bell catalanesc del món", junto al escepticismo que algunos estudiosos posteriores han mostrado por esa histórica frase nos ha llevado a la consideración y estudio de una serie de documentos escritos en Murcia, algunos de ellos relacionados con la Corona, y la mayor parte referentes a contratos y donaciones realizados por particulares.

Para llevar a cabo el trabajo hemos utilizado documentos excelentemente transcritos por Juan Torres Fontes y editados por la Academia "Alfonso X el Sabio" en el volumen II de la colección de "Documentos para la historia del Reino de Murcia", Documentos del siglo XIII. En alguna ocasión hemos acudido a comprobar personalmente en el manuscrito original las grafías y lecturas que presentaban problemas.

(*) Estos aspectos quedan estudiados con mayor amplitud en nuestra memoria de Licenciatura: Estado de lengua en Murcia entre los años 1243-1283, trabajo inédito, Facultad de Filosolia y Letras, Murcia, 1975, 132 fols. 
Para estudiar la situación lingüistica hemos dividido los documentos en dos épocas:

a) 1243-1266. Esta primera época abarca desde la llegada de Alfonso $\mathrm{X}$ de Castilla hasta la de Jaime I de Aragón.

b) 1266-1283. Este segundo período está centrado en la influencia de los repobladores que vinieron con Jaime I, puesto que Sancho IV de Castilla llega en 1284. De esta segunda época hemos utilizado un número mayor de documentos.

A través de los documentos de las dos épocas marcadas hemos estudiado el estado de lengua de cada una de ellas, con el fin de rastrear la influencia del catalán en Murcia, y comprobar si es tan notable que justifique la afirmación antes citada del cronista catalán.

\section{NOTAS A LOS DOCUMENTOS}

A lo largo del presente trabajo hemos conservado y utilizado la ordenación cronológica y la numeración de los documentos realizada por Juan Torres Fontes y según aparece en la edición de la Academia "Alfonso X el Sabio" (1).

\section{PRIMERA EPOCA:}

Documento II:

Murcia, 1243.-“Donación del maestre don Pelay Pérez al comendador Gil Gómez del Castillo de Paracuellos".

(1) TORRES FONTES, J.: Documentos del siglo XIII, Col. de documentos para la historia del Reino de Murcia, Academia Alfonso el Sabio, Murcia, 1969. 
Vocales:

Ŏ tónica diptonga: nuestro

No diptonga: Paracollos, ortos, fontes, uostros, depos.

Sabemos que $\mathrm{O}$ tónica deja de diptongar en gallego-portuglés y catalán (2).

$\breve{E}$ tónica: diptonga: bien

no diptonga: $e u$ (> ĕgo). La forma $e u$ del pronombre personal de primera persona es característica del gallego.

Consonantes.

- LL - latina aparece escrita - L- grafía propia de Aragón y Cataluña: sielos, seeladas, Caualeria.

Las demás vocales y consonantes ofrecen un desarrollo normal castellano.

Dado que este documento está sin firmar podríamos pensar por las vacilaciones en las vocales y consonantes que el escribano procediera, 0 tuviera contacto, con Galicia o Portugal.

Documento XVIII:

Cartagena, 1256.-“Doña Seguina dona la alquería de Alachah al obispo y Cabildo de Cartagena".

Este documento, firmado por Dominici Vele, ofrece las siguientes particularidades:

(2) MENENDEZ PIDAL, Gramática bistórica. Edit. Espasa-Calpe, Madrid, 1968, 13.^ edic. \& 13, pág. 61 . 


\section{Consonantes:}

M'N aparece escrita $\mathrm{N}(3)$ : dona.

-LL- la encontramos en lugar de -L-: sallidas.

C’T > YT, resultado propio de Aragón, etc.: espleytedes.

También observamos algunos casos de apócopes acabadas en -nt: dent, dest.

Documento XX:

Murcia, 1262.- "Entrega del castillo de Castalia, conforme convenio entre Jaime I y Ceyt Abuzeyt".

El presente documento aparece firmado por Jacme, "scriuano público en Murcia...".

Vocales:

El diptongo ié se convierte en iá. Este cambio es usual en Aragón: conveniancas. La vacilación del escribano se observa en otros dos ejemplos: conuenencias, con $\breve{e}$ sin diptongar (4), y conueniencias, que presenta un desarrollo castellano ( $\check{\mathrm{e}}>\mathrm{ié})$.

El resto de las vocales, tanto tónicas como átonas, diptongan o permanecen según la norma castellana.

\section{Consonantes:}

Presentan una evolución propia del castellano. salvo las siguientes:

-L-: Se palataliza en fielldat, pero se conserva en voluntat.

(3) $\mathbf{N}$ es la grafía simplifiacada de $\mathbf{N}$ usual en Cataluña.

(4) conuenencias: E deja de diptongar sólo en Cataluña y Galicia. 
-LL-: Aparece escrita con la grafía simplificada -L- en seelos, caualero; sin embargo, Jacme escribe -LL- en castiello, villa.

M'T: No sonoriza la $\mathrm{T}$ en comte (5), mientras que las restantes sonorizaciones las cumple.

Como ocurre con las vocales, la evolución de las demás consonantes es castellana.

Observando los antroponónimos Arnalt de Monzón, Bernat Eximénez, Jacme, etc.; teniendo en cuenta que se trata de un documento redactado entre Aragón y Murcia y, por último, las vacilaciones en la escritura entre castellano (mayor proporción), catalán y aragonés, podemos atribuir los idiolectalismos a las dudas del escribano que, posiblemente, fuera bilingüe.

\section{Documento XXI:}

Alicante, 1264.-“Censo otorgado por don Martín González, canónigo de Cartagena, a Pedro de Savardú de un cementerio de moros en Alicante".

Documento firmado por Pedro Raolf, "escriuano público en Alicant, que esta carta fiz escriuir...".

\section{Vocales:}

Observamos un sólo caso de no diptongación de $\breve{\mathrm{E}}$ tónica: Castella, frente a otros muchos de diptongación: arrendamiento, çiempre, diez...

Consonantes:

L-inicial aparece palatalizada en formas catalanas: die llunes. Los restantes casos de L tanto inicial como final se conservan inalterados.

(5) comte es uno de los únicos casost en que el catalán no sonoriza ia $T$ del grupo $m$ 't. 
-L- intervocálica. Aparece escrita con grafía -LL- en sallidas y ciellos. $-V$ final pasa a -ff: nueff.

La evolución más significativa de los sonidos empleados en este documento es el trueque de sibilantes: senso, semiterio, simiterio, serca, assençar, assenssamiento; çiempre.

El presente documento no ofrece otras particularidades.

Documento XXX:

Murcia, 1.266.-"Declaración de obediencia de los moros de Murcia a Alfonso X".

Este documento no especifica el nombre del escribano.

Particularidades:

Vocales:

Aféresis de la vocal átona inicial en bispos; en los restantes casos se mantiene siempre.

í átona se conserva en siello.

Consonantes:

El grupo CT > YT: feyta, mientras que el grupo ult > uch: mucho, de donde se deduce que los grupos consonánticos vacilan.

El grupo PT se conserva sin asimilar por latinismo: escripta, escriptura.

-d: se pierde alguna vez: mercé, que alterna con merced. 


\section{Grafías:}

$\widehat{N}$ : YN, grafía invertida aragonesa: seynor, juyno, d'Espayna. Junto con ella aparece NN, propia de Castilla: annos.

LL : yll. grafía complicada usual en Cataluña y Rioja: Casteylla. Como en el caso de encontramos grafías propiamente castellanas: caualleria, siello.

\section{SEGUNDA EPOCA:}

Documento $X X X V$ :

Villena, 1267.-“Infante don Manuel confirma a Elche sus privilegios, concede el fuero de Sevilla y otras mercedes".

Firmado por Pedrianes, presenta las siguientes alternancias:

Vocales:

E tónica. No diptonga: sempre, infernos, dizembre.

Diptonga: trezientos, tiempo, heredamientos, etc.

$$
\begin{aligned}
\text { Alterna: } & \text { pendiente }(\breve{\mathrm{e}}>\mathrm{ié}) \\
& \text { pendente }(\breve{\mathrm{e}}>\mathrm{e})
\end{aligned}
$$

Grafías:

N : GN, grafía propia de Cataluña (6), aparece en segnorio. NN, grafía castellana: annos, donna, empennar, sennor.

$L L$ : $L$, grafía que posiblemente se debe bien a confusión de $L$ y $L L$, bien a pronunciación latinizante: querelas. Frente a este caso hallamos LL en cauallos, omecillo, seello, ellos, etc.

(6) Sobre la grafía GN, véase MENENDEZ PIDAL: Origenes del español. Edit. EspasaCalpe. Madrid, 1968, 6.a edic. \& 4, 4, pág. 51 . 
Documento XXXVII:

Murcia, 1268.-"Acensamiento de una tienda en la calle de San Nicolás a María Serrana de Teruel".

El documento no aporta el nombre del escribano que lo realizó. De él podemos hacer las siguientes observaciones:

Vocales:

$\breve{E}$ tónica no diptonga en sempre. Este caso alterna con otros muchos de diptongación: tiene, obligamiento, çielo, etc.

Consonantes:

Sonoriza - $T$ - en fadiga. Esta sonorización se conoce en castellano popular antes de Juan Ruiz, Arcipreste de Hita, que la usa en varias ocasiones. También se halla en documentos aragoneses (7).

Palataliza -L final en abrill, mientras que la conserva sin palatilizar en $a l$, del, el, poral, etc.

Presenta antropónimos con ciertos grupos consonánticos interiores y finales extraños al castellano: Guillem de Montblanc, $O$. Porçell, etc. cuya procedencia es fácil de conocer.

Vocaliza la consonante final en san Nicolau; este fenómeno es propio del catalán.

Grafías:

N : NY, grafía propia de Cataluña: anyos, anyo.

(7) J. COROMINAS: Diccionario critico etimologico de la Lengua castellama. 4 vols. B.R.H. Edit. Gredos, Madrid, 1955-1957. 
LL : L, en aquelos. Alterna con la castellana LL: seellar...

\section{Documento XXXIX:}

Elche, 1269.- "Infante don Manuel confirma la partición de las casas y heredades de Elche".

Este documento no está firmado. Sus caracteres son castellanos excepto la falta de diptongación de $\breve{\mathrm{E}}$ tónica en pendente, que alterna con voces como siempre, tienen, bien, etc.

Grafías:

Sólo una vez se invierte el diptongo ei : vyent.

Documento XLI:

Villena, 1270.-“'Infante don Manuel al Concejo de Elche. Donación de dos hilas de agua".

Firmado por Per Yuannes, no ofrece ninguna particularidad.

Documento XLII:

Villena, 1270.- "Infante don Manuel al Concejo de Elche. Concediéndoles todas las franquezas que Alfonso $\mathrm{X}$ había concedido a la ciudad de Murcia".

Como el anterior, está escrito por Per Yuannes, y los rasgos que nos ofrece son castellanos. 
Documento XLIII:

Villena, 1270.-“Infante don Manuel al Concejo de Elche.-Otorgando y confirmando la partición de casas y heredamientos".

Presenta, como los documentos XLI y XLII, rasgos castellanos. El escribano también es Per Yuannes.

Documento XLVI:

Murcia, 1271.- “Composición entre don García Martínez, electo de Cartagena, y don Gregorio y doña Guiralda de Santa Fe por los diezmos de Alcaudete".

No especifica el nombre del escribano. Su única particularidad es la alternancia en la diptongación y falta de la misma en las vocales tónicas E y

E: No diptonga en setembre, festa.

Diptonga: diezmos, bien, mientre, etc.

Ŏ: No diptonga en uostro, uostra, nostro.

Diptonga en jueues, despues, etc.

Documento XLVII:

Murcia, 1272.- "Los pobladores de Zeneta a Alfonso X. Otorgándose por pagados del cambio de tierras que el rey les había hecho".

Documento firmado por Arnalt de Luçan. Como el anterior, sólo presenta alguna particularidad en la diptongación de $\breve{E}$ y $\breve{O}$ breves tónicas. Los casos de no diptongación son inferiores a los de evolución castellana.

Е: No diptonga en emenda.

Diptonga: heredamientos, firmamiento, otorgamientos, etc. 


\section{Ŏ: No diptonga en uostra, uostras. \\ Diptonga en buena, nuestros, etc.}

La antroponimia nos indica el origen catalán o similar de los pobladores que mandan hacer el documento, así como el de los testigos y el del propio escribano: Pero d Alost, Bernat de Touirans, Arnalt dez Tuytos, Jacme de San Nicolau, Pero Catalán de Xátiua, Bernat de Uernet, etcétera, etc. (8).

\section{Documento XLVIII:}

Murcia, 1272.-“Los clérigos parroquiales de Murcia a Alfonso X. Prometiendo celebrar una misa todos los sábados en la capilla del Alcázar de Murcia por las almas de sus padres y familiares".

El presente documento no aparece firmado.

Podemos hacer las siguientes observaciones:

Vocales tónicas:

E: No diptonga: Castella.

Diptonga: bien, capiella, etc.

Ŏ: No diptonga: uostros, wostra.

Diptonga: buena, nueua, etc.

Consonantes:

El grupo CT > YT, evolución propia de Aragón, aparece en eleyto. El resultado catellano $\mathrm{CH}$ alterna con YT: fecha, fechada.

(8) M. GUAI CAMARENA: La Corona de Aragón en la repoblación murciana. VII Congreso de la Corona de Aragón, Crónica, Ponencias y Comunicaciones. Vol. II: Comunicaciones, Barcelona, 1962. Págs. 303-310. Dicho trabajo sirve de referencia para lo relativo a ciertos aspectos de la antroponimia. 


\section{Antroponimia:}

Como en otros documentos, podemos observar a través de ella la procedencia catalana de los repobladores: Pero Tomé, Berenquer Robert, Bernat Celort, Bernat de Menor, Martín e Bernat Riquelm, etc. Todos ellos eran clérigos. Los nombres de las iglesias de las que eran titulares están catalinizados: Sant Lorenz, Sant Bertholomeu, Sant Pere; por el contrario, los nombres de otras se mantienen: Sancta Catalina, San Johan del Real, etc.

Documento XLIX:

Elche, 1272.-“Infante don Manuel concede a Elche los fueros y privilegios que tenía Murcia”.

Este documento no presenta influencias de ningún tipo. El escribano es Per Yuannes, como en los anteriores XLI, XLII, XLIII, que también eran obra suya.

\section{Documento $L$.}

Murcia 1272.-_Don García Martínez, electo de Cartagena y el Cabildo a Alfonso X. Dándose por pagados de las diez alquerías que les había tomado el rey, por las trescientas alfabas que les entregaba".

El presente documento aparece firmado por Guillem de Cabannas.

Presenta las siguientes particularidades:

Vocales:

Alternan la diptongación y la falta de la misma en los ejemplos referentes a $\stackrel{\mathrm{E}}{\mathrm{y}} \mathrm{O}$ tónicas: 
$\breve{\mathrm{E}}$ : No diptonga en terra.

Diptonga: siempre, quinientos, uinieren, etc.

Ŏ: No diptonga: pobla, uostra, uostros, nostra.

Diptonga: buena, fuero, etc.

Consonantes:

CT > YT: eleyto, que alterna con $\mathrm{CT}>\mathrm{CH}:$ fecha...

Antroponimia:

La antroponimia, como en otros documentos, nos indica el origen de los repobladores. En este caso son castellaons, y sólo el escribano es de origen catalán.

\section{Documento LI:}

Murcia, 1272.-"García Domínguez y Juan García de Toledo, partidores de Murcia, a don Ibáñez y Doña Toda. Concesión de cinco alhabas de heredad en la huerta de Murcia".

Este documento no especifica el nomber del escribano. Las particularidades se reducen al tratamiento de $\breve{\mathrm{E}}$ y $\breve{O}$ tónicas:

$\breve{E}$ : No diptonga en emenda, único caso en este documento.

Diptonga en oriella, siempre, etc.

Ŏ: No diptonga en uostra, Diptonga en nuestra, buen. 


\section{Documento LII:}

Murcia, 1272.-“Concesión de doña Ramoneta de Belloc, viuda de Bernal Cadireta, de la mitad de los bienes que habían pertenecido a su marido".

Este documento, como en ocasiones anteriores, está sin firmar.

Se observan las siguientes anomalías respecto al castellano:

Vocales:

$\breve{\mathrm{E}}$ : No diptonga en terra, pendente, tene, tenense.

Diptonga: heredamientos, enmienda, tiempo, siempre, etc.

Ŏ: No diptonga en nostro.

Diptonga en huerta, muerte, buenos, etc.

Consonantes:

$\mathrm{CT}>\mathrm{YT}$ en eleyto, mientras que evoluciona a $\mathrm{CH}$ en fecha, al igual que hemos visto en otros documentos.

$-\mathrm{L}>$-LL. Se apocopa la $-e$ final y al quedar la -1 en esta posición se palataliza, fenómeno propio del catalán.

Documento LIV:

Murcia, 1272.-“García Domínguez y Juan García de Toledo, partidores de Murcia, a Catalina de Calders. Entrega de tierras en compensación de las casas que le había ocupado".

Nos encontramos ante otro documento sin la firma de su realizador. La única anomalía que presenta es la falta de diptongación de Ŏ tónica 
en algunas voces mientras que las demás vocales y consonantes se desarrollan según las normas del castellano.

Ŏ no diptonga en nostros.

\section{Documento $L V$ :}

Lorca, 1273.- "Don Pelay Pérez, maestre de Santiago, se da por pagado de don Samuel, su judío de Montiel, de todo cuanto había recaudado por él".

El presente documento está firmado por Esteuan Lorenço, que "yo la mandé fazer por mandado del maestre...".

Sobre él podemos hacer las siguientes observaciones:

Vocales:

Su tratamiento es castellano, salvo en algunos casos $\mathrm{O}$ tónica no diptonga: nostro, nostros; conta alterna con cuenta y cuanta (9).

Consonantes:

Como las vocales, las consonantes evolucionan normalmente respecto al castellano, excepto en val, palabra típicamente catalana en la cual $l l$ final se reduce a $l ;-l l$ ha quedado en esa posición debido a la apócope medieval de $-e$.

Documento LVI:

Lorca, 1273.- "Don Pelay Pérez, maestre de Santiago, arrienda los derechos de la Orden en distintos lugares a tres judíos".

(9) ud es una forma usual del diptongo en Aragón. 
Documento anónimo. En él hallamos como únicas desviaciones de la evolución vocálica castellana la falta de diptongación en nostros, que alterna con numerosos casos de diptongación: Paracuellos, cuenta, etc.

\section{Documento LVII:}

Murcia, 1274.- -Jacobo de las Leyes vende una huerta en Sevilla a Juan Rodríguez". Este documento está firmado por Bernat Ermengol, de procedencia catalana.

Presenta las siguientes anomalías:

Vocales:

Diptonga $\breve{E}$ tónica cuando el castellano la mantiene por cultismo: presiente. Quizá se deba a una ultracorrección ya que el escribano duda en otros documentos en la diptongación de las vocales tónicas. Incluso vacila al escribir su nombre.

Las alteraciones nos indican una castellanización en el habla de los repobladores.

Consonantes:

En cuanto a las consonantes se refiere sólo hallamos una epéntesis de $y$ para evitar el hiato: poseyir, rayiz. Este fenómeno es propio de Aragón.

\section{Documento LVIII:}

Murcia, 1274.- -Entrega de tierras a censo por don Juan Pérez, chantre de Cartagena, a Pedro Rosell". 


\begin{abstract}
$\mathrm{Al}$ igual que el anterior, este documento aparece firmado por Bernal Ermengol.
\end{abstract}

Presenta los siguientes rasgos significativos:

Vocales:

$\breve{E}:$ No diptonga en terra.

Diptonga en siempre, ençienso, diez, trezientos, etc.

Consonantes:

Epéntesis de Y para impedir el hiato en posseyir, rayiz.

Grafias:

-l-: Confunde la grafía de la palatal $\left.\right|_{v}$ con la de -L- intervocálica: sallidas. En los casos de palatalización utiliza la grafía castellana.

-N-: NY, grafía catalana: senyal, alterna con la grafía castellana NN: annos:

Una prueba de que el escribano y notario Bernal Ermengol estaba castellanizado es que en el documento anterior apenas duda, en éste vacila alguna vez, pero en general sus textos son castellanos.

Documento LX.

Orihuela. 1274.-“Composición entre don García Martínez, electo de Cartagena, y el concejo de Orihuela sobre el pago de los diezmos".

Este documento no está firmado. La única observación sobre el desarrollo de los cambios fonéticos es el paso CT > YT, propio de Aragón, en eleyto. 
Documento LXI:

Lorca, 1275.- “Composición de don García Martínez, electo de Cartagena, y el concejo de Lorca. Sobre el pago de los diezmos de potros, becerros, muletos, pollinos y colmenas".

Documento, como el anterior, anónimo. Sobre él podemos decir que es castellano. La evolución de las vocales podemos decir que es normal, salvo en el caso $\breve{U}$ tónica, que no diptonga en bonos.

Consonantes:

El grupo CT interrumpe su evolución en el grado YT, en eleycto, mientras que resulta $\mathrm{CH}$ en ocho.

La apócope medieval produce algunos grupos consonánticos finales que no son habituales en castellano: daquent.

-L final, así como -L- intervocálica, por influencia catalana se palataliza en ell, dell, conpllidamyentre; estas formas alternan con el, del conplidamyentre.

Grafias:

Alternan la $i$ (e) y la $y$ en santa Eglesia y santa Yglesia, etc.

Documento LXII:

Murcia, 1275.--"Partición y deslinde de las seiscientas cincuenta tahúllas concedidas por Alfonso X al Obispo y cabildo de Cartagena".

Su autor es Bernardus Ermengaudi. Aunque su nombre aparece latinizado. a través de él se puede rastrear su origen catalán. 


\section{'Vocales:}

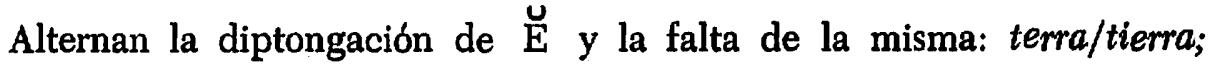
ponente/poniente.

Consonantes:

Asimila el grupo CT a T: fitas. Este mismo grupo resulta en alguna ocasión YT: eleyto; otras veces, por el contrario llega al grado castellano CT: derecha.

Pierde la $-n$, fenómeno general en catalán, en marge.

Por todo lo demás, el desarrollo de los grupos consonánticos es castellano.

Documento LXIII:

Murcia, 1276.-“Infante don Manuel confirma las particiones de Elche".

El presente documento está firmado por Bernald: "yo Bernald la fiz escriuir".

Su única particularidad es que palataliza la consonante $-\mathrm{L}$ final: dell, aunque no ocurre siempre, puesto que también aparece del.

Grafías:

N : Aparece GN y NN: signa, uignas, annos, empennar.

Como en los restantes documentos, la vacilación en las grafías, diptongos, etc., es una constante en los documentos realizados por escribanos catalanes. 
Documento LXIV:

Murcia, 1276.- "Infante don Manuel confirma las donaciones concedidas a los herederos de Elche, exigiendo efectuaran vencindad y los pleitos se juzgaran ante sus alcaldes".

Está escrito por mandato de Pere Yuannes; en él sólo encontramos una vacilación en el tratamiento de $\breve{O}$ breve tónica: en uostro no diptonga, mientras que en fuero la $\mathrm{O}$ ha diptongado.

\section{Documento LXV:}

Murcia, 1276.- -Infante don Manuel concede dos mil quinientas tahúllas y el agua correspondiente al concejo de Elche y siete mil quinientas tahúllas a los nuevos pobladores".

Como el anterior está firmado por Pere Yuannes: "yo Pere Yuannes la fiz escriuir...".

\section{Observaciones:}

Sólo en un caso introduce una $y$ epentética con el fin de evitar un hiato: leialmentre.

Vacila en el uso de Z, S en poscición final: diez mill y dies mill. Los restantes casos de $z$ o $s$ finales siguen la norma castellana.

Documento LXVI:

Elche, 1276:-“Infante don Manuel a los pobladores de Elche. Donación de agua para riego que deberían partir por caballeraís y peonías". 
Su autor es Rodoriz Yuannes. Como única anomalía respecto del castellano hallamos una $\mathrm{Y}$ epentética $\mathrm{y}$ antihiática en leialmentre.

\section{Documento LXVII:}

Villena, 1276.- - Infante don Manuel otorga a Villena el fuero y franqueza de Lorca. Confirmada por su hijo Juan Manuel en Villena".

Escrito por Alfonso. Presenta una evolución vocálica castellana en su totalidad.

Consonantes:

Trueca S y Z: dise, fase, diesmo, tresientos, etc.

Grafias:

Alterna ey y ay para el diptongo ei: veynte, traynta.

\section{Documento LXXI:}

Murcia, 1280.--"Infante don Manuel confirma las donaciones de casas, heredades y aguas concedidas a Elche".

El presente documento está firmado por Rodrig Yuannes.

Observamos que vacila en la diptongación de Ŏ tónica: nostro/puedan, mientras que se mantiene firme la diptongación de $\underline{\mathrm{E}}$ tónica.

Consonantes:

Conserva finales pocos usuales en castellano, ya sea asimilados o mantenidos: adelan, segond. 
Documento LXXII:

Murcia, 1280.- "Infante don Manuel concede a Yecla el fuero y franqueza de Lorca. Confirmada por su hijo don Juan Manuel, Juan II, Enrique IV y Reyes Católicos".

Escrito por Pero Juan. Sus rasgos son completamente castellanos.

Documento LXXIV:

Elche, 1281.- "Infante don Manuel al adelantado del reino y almojarife de Elche. Ordenándole que respetaran los fueros y privilegios de Elche".

Está firmado por Johan Pérez de Toledo: "la fiz escreuir...".

Sus únicas particularidades se basan en la alternancia y confusión de grafías castellanas y catalanas:

-L-: Escribe $L L$ en sallidas, mientras que aparece $L$ en diles.

N: Utiliza NN en annos, y NY en danyo.

\section{Documento LXXV:}

Elche, 1281.- "Infante don Manuel concede diversos privilegios y franquezas a los moros de Elche".

Su autor es Domingo Estevan. Sus rasgos son castellanos.

\section{Documento LXXVII:}

Chinchilla, 1281.- "Concejo de Chinchilla al Infante don Sancho. Ratificando su fidelidad y rogándole intercediera a su favor cerca de su padre". 
Desconocemos el nombre de su autor. Presenta un tratamiento castellano de las vocales y consonantes. La única excepción es la alternancia de la diptongación y ausencia de la misma en $\breve{O}$ breve tónica: buenos/ bonos.

\section{CONCLUSION}

Aun cuando se conceda bastante importancia al hábito lingüístico y a la procedencia de las personas que escribieron todos los documentos -que hemos estudiado detenidamente-, observamos que casi todos ellos presentan unos rasgos semejantes. Tanto los que están realizados por escribanos cuyo origen catalán suponemos, como los llevados a cabo por autores de antropónimo castellano, o aquellos otros que han llegado a nosotros como anónimos - y cuya cantidad es considerable-; todos ellos presentan un número mayor de rasgos castellanos que catalanes o aragoneses.

Los documentos son esencialmente castellanos, puesto que las desviaciones con respecto a éste que aparecen en algunos de ellos se reducen a alternancia de formas:

a) En lo referente a las vocales conviene destacar especialmente la realización o no de la diptongación de la $\breve{\mathrm{E}}$ y $\breve{\mathrm{O}}$ tónicas.

b) En cuanto a las consonantes, las irregularidades con referencia al castellano son mínimas, y casi siempre están relacionadas con el fenómeno de la palatalización.

c) El otro rasgo estudiado, el uso de determinadas grafías, tampoco supone una diferencia notable del castellano. 
Las vacilaciones que hemos señalado en el párrafo anterior no sólo son frecuentes en los distintos documentos, sino que aparecen dentro de uno mismo. Ninguno de ellos ofrece mayor representación de rasgos catalanes, ni por supuesto, son catalanes parcial o totalmente.

Por lo tanto creemos que en Murcia no se hablaba catalán en estos años que ocupan el centro del siglo XIII y que esta lengua influyó de forma esporádica en ciertos fenómenos y ocasiones exclusivamente. Pensamos, por todo lo expuesto anteriormente, que la afirmación de Muntaner no tenía una base firme, por lo que hemos podido comprobar a través de los documentos de este período de cuarenta años.

El hecho de que aparezca un posible trueque de sibilantes con anterioridad a la fecha fijada para Castilla, no altera las conclusiones, puesto que también es posterior la época del seseo catalán, aunque quizá esté relacionado con él. 